\title{
The critical duration in spatial-frequency-dependent visible persistence and specific reading disability
}

\author{
W. L. SLAGHUIS \\ University of Tasmania, Hobart, Tasmania, Australia \\ and \\ W. J. LOVEGROVE \\ University of Wollongong, Wollongong, New South Wales, Australia
}

\begin{abstract}
The critical durations of spatial-frequency-dependent visible persistence in specific-readingdisabled and normal readers were investigated. For each group, two regression lines were fitted to the first and second components of visible persistence using the method of least squares. The point of intersection between these two slopes was taken as an index of the duration of Component 1 persistence. The two groups did not differ on this component, but they did differ on Component 2.
\end{abstract}

A number of reading studies have shown differences between specific-reading-disabled (SRD) children and normal readers in durations of visible persistence (Badcock \& Lovegrove, 1981; Lovegrove, Heddle, \& Slaghuis, 1980; Slaghuis \& Lovegrove, 1985, 1986). In these studies, the term visible persistence refers to the continued visibility of a stimulus after stimulus offset that is phenomenally indistinguishable from that occurring during the actual presence of the stimulus.

Visible persistence is influenced by stimulus variables in ways similar to ways in which other temporal properties of the visual system are influenced. Its duration is decreased by increased adaptation level (Haber \& Standing, 1970), increased luminance (Bowen, Pola, \& Matin, 1974), increased contrast (Bowling, Lovegrove, \& Mapperson, 1979), and increased spatial frequency (Bowling \& Lovegrove, 1980). It has also been shown that an inverse relationship exists between visible persistence and stimulus duration for durations up to $100-150 \mathrm{msec}$ (Bowling \& Lovegrove, 1980). The stimulus durations for which this relationship holds are similar to the durations over which time-intensity reciprocity (Bloch's law) occurs. Bowling and Lovegrove (1980) found that for each spatial frequency, visible persistence decreased linearly with a slope of approximately -.75 as stimulus duration increased. For longer stimulus durations, the rate of decline in visible persistence with increasing durations was reduced (regression slope of -.13). The stimulus duration at which the change in slope in the visible persistence

W. L. Slaghuis's mailing address is: Department of Psychology, University of Tasmania, P.O. Box 252C, Hobart, Tasmania 7001, Australia. W. J. Lovegrove's address is: Department of Psychology, University of Wollongong, P.O. Box 1144, Wollongong, New South Wales 2500, Australia. $\times$ duration relationship occurs is called the critical $d u-$ ration.

On the basis of the relationship between visible persistence and stimulus duration, Bowling and Lovegrove (1980) proposed that visible persistence comprises two parts: Component 1 , which is peripheral, and Component 2 , which is central. The first component appears to reflect those mechanisms responsible for temporal integration within the peripheral visual system. The second component appears to be cortically located. Bowling and Lovegrove (1980) proposed that the two components in visible persistence are additive so that stimulus durations shorter than the critical duration measure a combination of both Components 1 and 2, and stimulus durations longer than the critical duration measure only Component 2.

The aim of the present experiment is to investigate the critical duration of visible persistence in SRDs and normal readers. This will show whether the reported differences between the groups are in Component 1 or Component 2 .

\section{METHOD}

\section{Subjects}

All SRD subjects were selected according to the following criteria. A SRD subject is defined here as a child of at least normal intelligence who has no known behavioral or organic disorder and who, despite normal schooling and average progress in other studies, has a reading delay of at least 2.5 years. All control subjects were selected according to the above criteria, except that their reading abilities were average or above average.

Each control subject was initially tested using the Junior Non-Verbal test of intelligence (Australian Council for Educational Research, 1950), the Neale Analysis of Reading Ability (Neale, 1966), and the Landolt C acuity chart. In addition to these tests, the SRD group was also assessed using the revised Wechsler Intelligence Scale for Children (WISC-R; Wechsler, 1974). A total of 12 male control and 12 male SRD subjects were included. The control and SRD groups had mean ages of 12 years, 
4 months and 12 years, 5 months and reading ages of 12 years, 1 month and 8 years, 8 months, respectively. The SRD group had a mean reading delay of 3 years, 9 months, which was found to be significantly different from that of the control group $[t(24)=14.7, p<.01]$. The mean Junior Non-Verbal IQs for the SRD and control groups were 109.5 and 99.9, respectively, and these were not significantly different from each other $[t(24)=2.93, p>.05]$. The mean WISC-R subscale IQ scores for the SRDs were 97.4 for the verbal IQ, 104 for the performance IQ, and 100.2 for the full-scale IQ. Both groups had normal Landolt $\mathbf{C}$ acuity, and no subject suffered from any organic disorder or gross behavioral disorder.

\section{Stimuli and Apparatus}

Full details of stimuli and apparatus are given in Slaghuis and Lovegrove (1985).

\section{Procedure}

Full details of the measurement of visible persistence are given in Slaghuis and Lovegrove (1985).

The data were analyzed using a three-factor analysis of variance, with reading ability being the between-groups factor. Subjects received all combinations of the other factors (spatial frequency, duration). Visible persistence durations were obtained for each subject at spatial frequencies of 2 and 12 cycles per degree (cpd), with a contrast level of 0.3 , and at 9 stimulus durations $(60,80,100,120,140,160,180,200$, and $300 \mathrm{msec}$ ). The order of presentation was counterbalanced, and all stimuli were presented binocularly.

\section{RESULTS AND DISCUSSION}

The log transformed means for each group as a function of duration are shown in Figure 1.

A three-way analysis of variance resulted in a nonsignificant groups main effect $[F(1,22)=22.01, p>.05]$, indicating that there were no overall differences in visible persistence between the groups.

Main effects of spatial frequency $[F(1,22)=263.9$, $p<.01]$ and duration $[F(1,22)=312.7, p<.01]$ were both significant, indicating, respectively, that visible persistence durations increased with increasing spatial frequency and decreased with increasing stimulus duration.

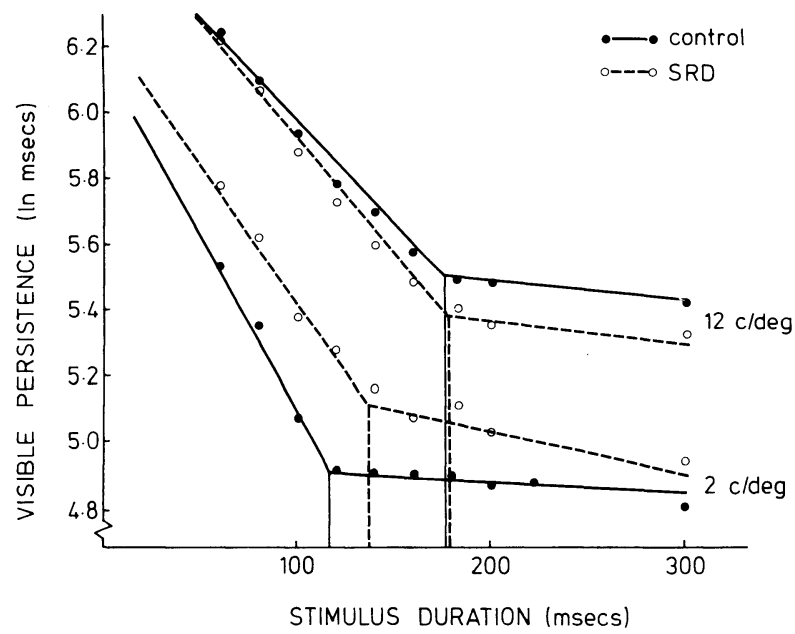

Figure 1. Visible persistence durations (In milliseconds) as a function of duration, spatial frequency, and group. The points of intersection between the fitted vertical lines and the $x$ axis represent the critical durations for each condition.
Table 1

Mean Regression Slopes and Standard Deviations for Components 1 and 2 at Spatial Frequencies of 2 and 12 cpd and Mean Critical Durations for the Specific Reading and Control Group

\begin{tabular}{|c|c|c|c|c|c|c|c|}
\hline \multirow[b]{3}{*}{ Group } & \multirow[b]{3}{*}{ cpd } & \multicolumn{4}{|c|}{ Regression Slopes } & \multirow{2}{*}{\multicolumn{2}{|c|}{$\begin{array}{c}\text { Critical } \\
\text { Duration }\end{array}$}} \\
\hline & & \multicolumn{2}{|c|}{ Component 1} & \multicolumn{2}{|c|}{ Component 2} & & \\
\hline & & Mean & $S D$ & Mean & $\overline{S D}$ & Mean & $S D$ \\
\hline Control & $\begin{array}{r}2 \\
12\end{array}$ & $\begin{array}{l}-1.71 \\
-2.78\end{array}$ & $\begin{array}{l}.68 \\
.72\end{array}$ & $\begin{array}{l}-0.11 \\
-0.34\end{array}$ & $\begin{array}{l}.09 \\
.34\end{array}$ & $\begin{array}{l}123.20 \\
148.24\end{array}$ & $\begin{array}{l}18.5 \\
24.4\end{array}$ \\
\hline SRD & $\begin{array}{r}2 \\
12\end{array}$ & $\begin{array}{l}-2.05 \\
-3.12\end{array}$ & $\begin{array}{r}.96 \\
1.24\end{array}$ & $\begin{array}{l}-0.30 \\
-0.32\end{array}$ & $\begin{array}{l}.20 \\
.25\end{array}$ & $\begin{array}{l}128.75 \\
145.62\end{array}$ & $\begin{array}{l}21.3 \\
25.5\end{array}$ \\
\hline
\end{tabular}

Note-In summary, these results replicate previous findings by showing that SRDs and control subjects differ from each other in terms of the slope of the spatial frequency $\times$ visible persistence function. They extend previous findings by showing that these differences are in Component 2 and not Component 1 persistence. This localizes the site of the differences as being in the visual cortex and not some lower site.

As expected on the basis of previous research, the groups $\times$ spatial frequency interaction was significant $[F(1,22)=19.34, p<.01]$, indicating that visible persistence durations across spatial frequency were different for the groups (Badcock \& Lovegrove, 1981; Lovegrove et al., 1980; Slaghuis \& Lovegrove, 1985, 1986). The results were further investigated by determining the critical duration for each subject at each spatial frequency. This was done for each subject by fitting two linear regression lines using the method of least squares. The point of intersection of these two lines was taken as the critical duration in each case. The results are shown in Table 1. An analysis of variance of these points showed that the groups did not differ from each other $[F(1,22)=.05$, $p>.05]$. The critical durations for 2 and $12 \mathrm{cpd}$ were significantly different from each other $[F(1,22)=9.8$, $p<.01]$. The critical duration was significantly longer for $12 \mathrm{cpd}$ than for $2 \mathrm{cpd}$, as has been shown previously. The interaction between groups and spatial frequency was not significant. $F$ s and $t s$ show that although the groups differ in the slope of their visible persistence $\times$ spatial frequency functions, these differences do not occur in Component 1 . Instead, they occur in Component 2 or cortical visible persistence.

\section{REFERENCES}

Australian Council for Educational Research. (1950). Junior Non-Verbal Test. Hawthorne, Victoria, Australia: Author.

BADCOCK, D., \& LoVEGROVE, W. J. (1981). The effect of contrast, stimulus duration and spatial frequency on visible persistence in normal and specifically disabled readers. Journal of Experimental Psychology: Human Perception \& Performance, 7, 495-505.

Bowen, R. W., Pola, J., \& Matin, L. (1974). Visual persistence: Effects of flash luminance, duration and energy. Vision Research, 14, 295-303.

Bowling, A., \& Lovegrove, W. J. (1980). The effects of stimulus duration on the persistence of gratings. Perception \& Psychophysics, 27, 574-578.

Bowling, A., \& Lovegrove, W. J., \& Mapperson, B. (1979). The effect of spatial frequency and contrast on visible persistence. Perception, 8, 529-539.

HABER, R. N., \& STANDING, L. (1970). Direct measures of the apparent duration of a flash. Canadian Journal of Psychology, 24, 216-229. 
Lovegrove, W. J., Heddle, M., \& Slaghuis, W. L. (1980). Reading disability: Spatial frequency specific deficits in visual information store. Neuropsychologia, 18, 111-115.

Neale, M. D. (1966). The Neale Analysis of Reading Ability. London: Macmillan.

Slaghuis, W. L., \& Lovegrove, W. J. (1985). Spatial-frequencydependent visible persistence and specific reading disability. Brain \& Cognition, 4, 219-240.
Slaghuis, W. L., \& Lovegrove, W. J. (1986). The effect of physical flicker on visible persistence in normal and specifically disabled readers. Australian Journal of Psychology, 38, 1-11.

WeChSLER, D. (1974). Wechsler Intelligence Scale for ChildrenRevised. New York: The Psychological Corporation.

(Manuscript received for publication July 21, 1986.) 